\title{
O direito humano à aprendizagem e a aprendizagem dos direitos humanos
}

\section{The human right to learning and the learning of human rights ${ }^{1}$}

\author{
Tristan McCowan²
}

\begin{abstract}
RESUMO
A educação em direitos humanos está contida em uma variedade de instrumentos de direito internacional, e tem se tornado predominante na educação formal e não formal a nível mundial. No entanto, há uma incerteza considerável - de natureza conceitual e prática - sobre a forma como a educação em direitos humanos relaciona-se com o próprio direito à educação. Este artigo apresenta um argumento para a inseparabilidade dos dois, passando por três fases: primeiro, um esboço dos componentes essenciais do direito à educação; segundo, uma justificação do papel da educação em direitos humanos; e terceiro, uma exploração das interligações. Aprender sobre, para e através dos direitos humanos pode ser visto como parte inerente do direito à educação, concebido de modo amplo, tendo por base as ideias de Freire sobre o caráter político da educação em sua totalidade. Em última análise, a linha entre a prática dos direitos humanos e da aprendizagem dos direitos humanos torna-se tênue, levando a uma expressão integrada e cíclica do desenvolvimento humano.
\end{abstract}

Palavras-chave: empoderamento; direitos humanos; educação em direitos humanos; Paulo Freire; direito à educação.

\begin{abstract}
Human rights education is contained in a range of international rights instruments, and has become increasingly prevalent in both formal and non-formal education across the world. However, there is considerable uncertainty - of a conceptual and practical nature - as to how human rights education relates
\end{abstract}

DOI: $10.1590 / 0104-4060.39818$

1 Tradução feita por Sônia Fátima Schwendler.

2 Universidade de Londres. London, United Kingdom, 20 Bedford Way. WC1H 0AL. 
to the right to education itself. This article puts forward an argument for the inseparability of the two, passing through three stages: first, an outline of the fundamental components of the right to education; second, a justification of the role of human rights education; and third, an exploration of the interlinkages. Learning about, for and through human rights can be seen as an inherent part of the right to education broadly conceived, taking into account Freire's ideas on the political character of all education. Ultimately, the line between the practice of human rights and the learning of human rights becomes fainter, leading to an integrated and cyclical expression of human development.

Keywords: empowerment; human rights; human rights education; Paulo Freire; right to education.

\section{Introdução}

O direito à educação é caracterizado pelo elevado nível de consenso popular quanto à sua existência, combinado com um grau surpreendente de contestação e indeterminação quanto ao seu conteúdo. Mas estas questões são de fato relevantes? É realmente significativo questionar se a educação é ou não é um direito humano? Se pudermos concordar que a educação é importante por diversas razões, e conseguirmos reunir os recursos necessários para viabilizar seu amplo acesso, seria apenas uma mera curiosidade filosófica questionar se a educação é ou não é um direito absoluto? Na verdade, esta é a abordagem da Educação para Todos (EPT), lançada em Jomtien, na Tailândia, em 1990, que envolveu uma variedade de diferentes agências, entre elas, o Banco Mundial, que não aborda a educação como um direito fundamental, mas, no entanto, apoia a expansão dos sistemas escolares. Consequentemente, pesquisas em torno da EPT têm focado na complexidade da implementação, no desafio do acesso e permanência das crianças na escola, ao invés de questionamentos de porque nós necessitamos em primeiro lugar da educação e da escola. Considerando que há um consenso de que a educação é crucial, sem a concordância de porque, à primeira vista, o foco na implementação pode parecer como uma excelente estratégia. No entanto, vou argumentar que este não é o caso. É relevante discutir por que valorizamos a educação e se realmente a consideramos como um direito humano.

A primeira razão é uma das fragilidades das justificativas instrumentais. Se o acesso à escola somente se justifica com base no custo-benefício, de que a taxa de retorno para a escola justifica o investimento, é provável que haja um amplo 
acesso à escolarização, mas não o acesso universal, levando à total exclusão de determinadas camadas populacionais ao redor do mundo. A EPT e os Objetivos de Desenvolvimento do Milênio trabalham com a ideia de metas ao invés do direito, sendo a primeira uma aspiração para um momento futuro, ao invés de uma obrigação moral e política imediata. Embora esta questão do acesso e da marginalização seja fundamental para a discussão dos direitos educacionais, este não será o tema deste artigo.

A segunda razão é a importância que damos à educação - longe de uma questão esotérica, mas surpreendentemente muitas vezes esquecida - é que não existe uma coisa única chamada educação. A educação se expressa em formas múltiplas e muitas vezes contraditórias; muito do que é desenvolvido nas escolas em todas as regiões do mundo geralmente é sem sentido e, em alguns casos, extremamente prejudicial aos educandos. Mesmo em ambientes considerados positivos, em que ocorre certo nível de aprendizado, há visões conflitantes sobre o que a educação almeja e como ela é organizada. É este segundo ponto que vou abordar neste artigo. A posição assumida pelas agências multilaterais no contexto internacional muitas vezes é aquela que, enquanto não podemos concordar com tudo, podemos avançar com as escolas convencionais que desenvolvem as competências básicas da alfabetização e da matemática. Em vez disso, vou argumentar que há contornos muito mais substanciais em relação às metas e os processos de educação que exigem compromissos em nível internacional. Estes aspectos dizem respeito, essencialmente, à dimensão ética na educação, aqui expressa em relação aos direitos humanos. Portanto, a pergunta que nos resta é a relação entre as justificativas para a educação e os seus conteúdos, ou entre o direito humano à aprendizagem e a aprendizagem dos direitos humanos.

De modo controverso, talvez, vou argumentar contra a lógica convencional associada à educação em direitos humanos (EDH): (1) Para que haja direitos humanos precisamos saber o que eles são e ter a capacidade de reivindicá-los e exercê-los; (2) A educação pode proporcionar os conhecimentos, habilidades e valores necessários; (3) Portanto, há um direito à educação.

Como argumentarei a seguir, de modo mais detalhado, essa lógica cria uma separação muito grande entre a educação e os direitos humanos, abordando a educação como um tratamento que leva a um resultado específico. Uma visão alternativa compreende a existência de limites mais permeáveis entre a educação e os direitos humanos.

Este artigo baseia-se no material do livro Educação como um Direito Humano (McCOWAN, 2013), e inicia sintetizando argumentos lá apresentados em justificativas para o direito geral à educação. Com base nisto, implicações são traçadas para a questão de saber se existe um direito especificamente para a EDH. Na sequência, abordarei a questão das formas que a EDH pode assu- 
mir dentro dessa concepção. Há questões importantes que não poderei discutir neste artigo, tais como a universalidade ou especificidade cultural dos direitos humanos; questões de eficácia da implementação do programa e convergência da política global. Ao invés disso, o foco estará nas justificativas fundamentais e nas conceptualizações de EDH.

\section{O que são direitos humanos?}

Na sua acepção mais básica, um direito é uma reivindicação justificada que um indivíduo (ou grupo) pode fazer aos outros, e um direito humano ou direito universal (os termos serão usados como sinônimos) é aquele que é mantido por todos os seres humanos e apenas por seres humanos, e não depende de cidadania nacional ou qualquer outro atributo.

Os direitos podem ser compreendidos em um sentido legal ou moral, ou seja, eles podem ser direitos que estão consagrados na lei (neste caso, o direito internacional) ou aqueles que consideramos serem justificáveis e válidos, mesmo que não tenham sido legalmente reconhecidos. Aqui vou seguir Amartya Sen (2004) e outros na compreensão de que os direitos são essencialmente morais, e sua consagração em lei é um processo secundário. Isso não quer dizer que a lei e a legislação não são importantes (ao lado de "agitação" e "reconhecimento" (SEM, 2004)); pelo contrário, elas são mecanismos essenciais para proteger a humanidade contra os abusos dos direitos. A questão é que a validade de um direito não deriva de sua natureza jurídica, nem o conjunto de direitos e o conteúdo dos direitos específicos se restringem à situação jurídica atual. Nossa concepção, portanto, não deve ficar confinada pelas expressões existentes nos instrumentos de direito internacional.

Ainda, seguindo a concepção de Sen, compreendo direitos como sendo essencialmente deliberativos. Ou seja, os direitos são construídos e sua validade testada através do debate público. É claro que seria ingênuo sugerir que as condições para a discussão aberta e horizontal existem nos distintos locais ao redor do mundo. No entanto, este fato empírico não enfraquece o princípio de que os direitos devem ser amplamente construídos e estabelecidos por meio da ratificação coletiva. Ambos os aspectos - que são principalmente moral e de caráter deliberativo - são essenciais para a educação, como será mostrado no decorrer do artigo.

Um último elemento é que os direitos humanos não são um esquema completo da justiça social. Eles fornecem proteções fundamentais para indivíduos e 
grupos, e asseguram as condições para a prosperidade humana, mas nós podemos muito bem ter preocupações que vão além dessas garantias. Particularmente, há considerações em relação à igualdade que não podem ser adequadamente tratadas. Isso não é uma falha dos direitos humanos, mas simplesmente nos alerta para o fato de que este, ainda que extremamente relevante, é apenas um dos elementos de uma série de considerações morais e políticas.

\section{Existe um direito humano à educação e à aprendizagem?}

Os seres humanos são tanto sensíveis como racionais. Nós sentimos o prazer e a dor, e ao contrário de muitos outros seres, somos conscientes desses sentimentos, e refletimos, planejamos e nos determinamos. Ao mesmo tempo em que somos extremamente vulneráveis temos uma capacidade e um potencial extraordinários. Em resposta, os direitos humanos proporcionam as condições que nos protegem de danos e ampliam as nossas capacidades. Às vezes, os direitos são divididos entre aqueles que se relacionam com o bem-estar e os que se referem à agência; o primeiro refere-se a esta proteção contra danos, o último visa assegurar nossa capacidade de tomar decisões sobre nós mesmos, mesmo se estas decisões resultarem num impacto negativo sobre nosso bem-estar. (Por exemplo, uma pessoa recusa uma oferta de uma compra lucrativa para a sua organização, de modo a manter o seu caráter filantrópico; ou por motivos religiosos, uma pessoa recusa tratamento médico recomendado pelos médicos).

A literatura (relativamente incipiente) em justificativas para o direito à educação em língua inglesa centra-se em dois elementos: socialização e autonomia (por exemplo, HAYDON, 1977; WRINGE, 1986). O primeiro refere-se, principalmente, ao bem-estar e o segundo à agência. Em primeiro lugar, precisamos de educação tendo em vista que a linguagem, os conceitos, conhecimentos e habilidades são fundamentais para a nossa sobrevivência básica na sociedade e na convivência com os outros. Em segundo lugar, a educação é essencial para fazer escolhas sobre as nossas próprias vidas, em função da necessidade de estarmos cientes de que há pontos de vista e modos de vida distintos. Ambos aspectos me parecem convincentes. No entanto, nenhum destes reconhece adequadamente outro aspecto essencial do ser humano, a capacidade de perceber e entender. A educação também é fundamental porque ela possibilita o nosso processo de compreensão do mundo e de nós mesmos. Minha própria concepção da base do direito à educação (seguindo Freire e outros) é composta pelos componentes duais da compreensão e da ação ética. Estes dois elementos se 
apoiam mutuamente, no sentido de que a compreensão progressivamente mais profunda do mundo amplia a nossa capacidade de agir, e a ação no mundo é um componente fundamental da aprendizagem e das funções que melhoram a nossa compreensão. (MCCOWAN, 2013).

Neste artigo não será possível fornecer um esboço mais aprofundado dessa concepção. Na verdade, os apontamentos que posteriormente faço sobre a EDH não se balizam sobre a concepção que acabo de definir. Alguma diversidade de pontos de vista do que é de valor na educação e na vida é, obviamente, tanto inevitável quanto desejável, e haverá muitas outras expressões válidas que fundamentam o direito à educação. Contudo, não é o caso de que qualquer concepção dará conta. Vou argumentar que existem certos princípios nos quais a diversidade de nossas concepções do direito à educação irá se sustentar. É com base nestes princípios que apresentarei um argumento para colocar a educação para os direitos humanos no âmbito do direito à educação.

A seguir apresento as quatro características essenciais da educação entendida como um direito humano: 1) valor intrínseco; 2) engajamento em processos educacionais; 3) aproveitamento ao longo da vida; e 4) consonância com a totalidade dos direitos humanos.

1. Se a educação é considerada um direito, então ela deve ter um valor intrínseco. Se a educação possui apenas um valor instrumental, então ela não é em si mesma um direito, mas serve apenas como um suplemento para outros direitos. A maioria das discussões sobre o direito à educação - e as campanhas das agências de desenvolvimento - aponta para seu papel de suporte a outros aspectos do bem-estar (saúde, planejamento familiar, emprego, etc). Neste sentido, é um direito subjacente a todos os outros. (WALDRON; RUANE, 2011). Embora a educação de fato desempenhe esta função (que é uma função válida), para que ela seja em si mesma um direito há a necessidade dela possuir um valor intrínseco;

2. O direito à educação é um direito aos processos educativos, ao invés de ingressos ou resultados. Em particular, há problemas com a associação do direito com o acesso à escolarização. Além disso, o direito à educação não pode estipular resultados universais de aprendizagem, considerando os diversos valores envolvidos, a imprevisibilidade da educação e a necessidade da espontaneidade e da liberdade na aprendizagem. As pessoas têm o direito de participar de processos significativos de aprendizagem;

3. O direito à educação não pode ser limitado a um determinado período da vida. Enquanto a infância é de fundamental importância para a aprendizagem, o direito inclui todos os níveis de educação e tem uma aplicação ao longo da vida;

4. O direito à educação deve estar em consonância com outros direitos humanos. Deve ser conduzido de uma forma que não infrinja a integridade física 
dos alunos, a liberdade de pensamento e assim por diante (indivisibilidade dos direitos). Em conformidade com R. S. Peters (1966), existem restrições morais sobre o que se considera como educação. Deve ser caracterizada tanto pela consciência como pela disposição, em outras palavras, os alunos devem estar cientes de que eles estão envolvidos em um processo intencional de aprendizagem, e ter algum desejo para estar envolvido em tal processo (ou seja, excluindo lavagem cerebral, condicionamento, etc).

Quais são então as implicações desses princípios para a educação em direitos humanos? Para responder a isso, primeiro é necessário mapear brevemente o que se entende por esta noção.

\section{Educação em direitos humanos}

O livro de Monisha Bajaj Escolaridade e Mudança Social (2011) fornece um relato fascinante de experiências de educação em direitos humanos na Índia. Aqui vemos em detalhes vívidos a extensão da opressão e da discriminação sofrida por determinados grupos, o potencial transformador do EDH, bem como alguns dos riscos e a possibilidade de reação.

O livro analisa a experiência do Instituto de Educação em Direitos Humanos (IEDH), que possui um extenso programa envolvendo cerca de 4.000 escolas públicas de todo o país. O programa está trabalhando no contexto de extrema marginalização dos adivasis ou grupos tribais na Índia, e os dalits (conhecidos anteriormente como casta intocável). Os últimos, embora oficialmente ilegais, ainda estão confinados a trabalhos braçais e excluídos de locais religiosos e do contato com outras castas. Estes grupos se caracterizam pelo desempoderamento, combinando a ausência da educação formal e a consequente restrição do acesso tanto às informações quanto às oportunidades, o que assume um sentido profundamente arraigado da naturalização da sua inferioridade. Nas escolas, os alunos também enfrentam o castigo corporal, a falta de serviços básicos e a discriminação baseada no sistema de castas.

O programa EDH executado ao longo de três anos, em muitos casos, trouxe mudanças significativas para essa situação. As crianças começaram a agir sobre as questões de discriminação na comunidade, de evasão escolar, de infanticídio feminino, e do casamento precoce que impede as meninas de continuar seus estudos. No entanto, elas também enfrentaram oposição significativa de suas próprias famílias, e daqueles cujo poder e privilégios estavam sendo interrompidos. Tome esses dois exemplos: 
Um estudante Dalit da sétima série afirmou certo dia que usou a torneira para lavar seu prato e foi insultado por um senhor mais velho da aldeia de uma casta superior. Ele defendeu seu direito, mas ele e sua família foram ameaçados com violência. (BAJAJ, 2011, p. 84).

Um estudante da sexta série, aprendendo sobre os direitos humanos, pela primeira vez, foi para o diretor para reivindicar que ele não havia recebido um uniforme a que tinha direito; como punição, ele foi açoitado e ameaçado de expulsão. (BAJAJ, 2011, p. 84).

Esses exemplos mostram a coragem que é necessária para corrigir as injustiças que os alunos enfrentam. Também mostram a necessidade de julgamento e discrição, para distinguir entre a ação corajosa e a imprudência que colocará em risco eles próprios e aos outros. Outra importante área de aprendizagem através da ação foi a transformação das intervenções individuais em intervenções coletivas, dada a fragilidade e o aumento dos perigos das individuais.

Uma característica muito significativa identificada pelo estudo foi o papel dos 'agentes de coalizão', alunos relativamente mais privilegiados que desenvolvem solidariedade para e agem em nome de ou em conjunto com os colegas mais desfavorecidos. Apesar dos desafios para a implementação de um currículo orientado para exames e habilidades básicas, a EDH havia encontrado um lugar e estava possibilitando mudanças reais.

Manter essa vívida ilustração do contexto da EDH, na prática, em nossas mentes, nos permite olhar para o conceito de EDH. Na verdade, há uma considerável diversidade de interpretação e prática em EDH. Existem iniciativas nacionais de educação de direitos humanos em mais de 100 países (BAJAJ, 2011), embora com evidência generalizada de "dissociação", onde o conteúdo é higienizado de forma a não revelar-se demasiado difícil para as estruturas de poder existentes, ou empurrado para a periferia da experiência escolar. Há também uma longa tradição de EDH no trabalho das Organizações Não Governamentais - ONGs, da educação de adultos e da capacitação profissional.

É um ponto frequentemente ouvido que a afirmação seminal do direito à educação na Declaração Universal dos Direitos Humanos já incorpora a educação em direitos humanos. A segunda parte do artigo 26 afirma:

A instrução será orientada no sentido do pleno desenvolvimento da personalidade humana e do fortalecimento do respeito pelos direitos humanos e pelas liberdades fundamentais. A instrução promoverá a compreensão, a 
tolerância e a amizade entre todas as nações e grupos raciais ou religiosos, e coadjuvará as atividades das Nações Unidas em prol da manutenção da paz. (DECLARAÇÃO Universal dos Direitos Humanos, 1948).

Esses pontos são expandidos no artigo 29 da Convenção dos Direitos da Criança e, ainda, ratificados em uma série de outras declarações e documentos da Organização das Nações Unidas - ONU e de outras agências. A Carta do Conselho da Europa sobre a Educação para a Cidadania Democrática e a Educação para os Direitos Humanos de 2010 fornece a seguinte definição:

Educação em direitos humanos significa educação, formação, conscientização, informação, práticas e atividades que visam prover os alunos com conhecimentos, habilidades e compreensão e desenvolver suas atitudes e comportamentos, para empoderar os educandos para que contribuam com a construção e defesa de uma cultura universal dos direitos humanos na sociedade, na perspectiva da promoção e proteção dos direitos humanos e das liberdades fundamentais. (CARTA do Conselho da Europa..., 2010).

Aqui temos uma definição abrangente e precisa que nos auxilia no mapeamento do conjunto de práticas associadas à EDH. Ela é repleta de abordagens diversas, mas é distinta em sua referência para a construção de uma cultura de direitos humanos (essa referência também apareceu na posterior Declaração das Nações Unidas sobre a Educação e Formação em Direitos Humanos) indicando que além dos mecanismos do recurso legal, nós precisamos de um ambiente de apoio e respeito aos direitos humanos. Esta visão é certamente compartilhada por este artigo. A questão permanece sobre o melhor modo de formar e apoiar esta cultura, sobretudo considerando nosso ponto de partida desfavorável. Passamos agora para a questão central de por que nós queremos em primeira instância nos envolver em EDH.

\section{Por que a educação em direitos humanos?}

\section{a. Justificativas gerais}

$\mathrm{O}$ valor da educação em direitos humanos baseia-se no valor dos próprios direitos humanos. Não há espaço neste artigo para fornecer uma avaliação geral 
dos direitos humanos, e eu vou assumir aqui que os direitos humanos são de valor, e colocar minha preocupação na questão de saber se a educação em direitos humanos é desejável ou necessária. O movimento do primeiro para o segundo pode parecer simples e direto, mas, na verdade, há uma série de caminhos que podemos assumir.

Em primeiro lugar, podemos ver a educação em direitos humanos como tendo tanto benefícios sociais como individuais. A EDH pode ser vista como um meio de levar as pessoas a mudar suas atitudes e comportamentos de uma forma que será benéfica para toda a sociedade. Assim, um indivíduo pode desenvolver respeito pelas opiniões dos outros, reconhecer os interesses daqueles que estão fora da sua comunidade imediata, grupo étnico ou nacionalidade, e abster-se de submeter os outros, por exemplo, à agressão física ou humilhação psicológica. (Como será discutido na próxima seção, há dificuldades em utilizar esses benefícios para a sociedade como uma justificativa para o direito de EDH, mas eles são, no entanto, uma justificativa). A EDH também pode ser vista como um meio para a defesa dos direitos humanos do educando em si: a aquisição de informações sobre os instrumentos de direito internacional, o desenvolvimento de habilidades de comunicação para negociar com as autoridades competentes e as disposições para agir corajosamente em defesa de seus direitos. Nós geralmente pensamos na última forma como particularmente relevante para aqueles grupos que são significativamente desempoderados, e por causa da desvantagem econômica, da discriminação ou falta de voz, atualmente incapazes de reivindicar seus direitos legalmente reconhecidos.

A Educação também pode ser vista como tendo valor em relação aos atributos a serem desenvolvidos nos seres humanos e na sociedade. Como discutido na seção anterior, ela pode cumprir uma série de funções em relação aos direitos humanos: Informar as pessoas sobre elas mesmas; preparar as pessoas para exercitarem seus direitos; Incutir o seu valor; Capacitar as pessoas para participar de sua construção.

Esses diferentes papéis da educação podem variar em relação a três fatores: (1) A concepção subjacente dos direitos humanos; (2) O processo de realização dos direitos humanos na prática; (3) A compreensão da educação;

Então, compreendendo que os direitos humanos derivam de sua formulação legal (1) irá levar a um tratamento diferenciado nas escolas a partir de uma visão de que eles são estabelecidos através da luta popular, ou da discussão pública. $\mathrm{O}$ processo de capacitar os educandos na defesa dos direitos irá variar dependendo se seu processo de realização (2) é puramente uma questão legal, ou com base também na reivindicação, no protesto, nas interações cotidianas e no trabalho de organizações da sociedade civil. Por último (3), haverá diferenças a depender se 
a educação é entendida como um processo de transmissão de conhecimento, ou um de desenvolvimento da compreensão e construção coletiva do conhecimento.

$\mathrm{Na}$ verdade, justificativas para educação em direitos humanos aparecem fortemente em todos esses cenários, se nós adotamos uma concepção fixa ou maleável dos direitos humanos, ou uma concepção de educação bancária ou de construção do conhecimento. Numa perspectiva dos direitos humanos de cima para baixo as pessoas precisam ser informadas e adotar os valores relevantes; numa perspectiva de baixo para cima as pessoas precisam ser empoderadas para participar - ambas as perspectivas envolvem educação (embora de modo distinto).

Podemos ver claramente que EDH é desejável, mas será que é realmente essencial para a defesa dos direitos humanos? O questionamento se a educação é uma condição absolutamente necessária depende de como entendemos os direitos. Se focarmos no que é fornecido para o indivíduo pelo Estado, como a prestação de serviços, tais como cuidados de saúde, garantia de segurança e liberdade de perseguição religiosa, em certo sentido, tudo isso pode ser garantido na ausência da educação. No entanto, este é um tratamento muito passivo do cumprimento dos direitos, e ignora os elementos ativos do sujeito de direitos como alguém que faz uma reivindicação a outros, luta coletivamente para o reconhecimento de uma demanda, e faz a escolha de exercitar esse direito ou não. Neste sentido mais ativo, compreendendo o sujeito de direitos como alguém que reinvindica do Estado ao invés de simplesmente receber um serviço, então a educação é essencial, uma vez que é impossível desempenhar um papel ativo, sem as informações necessárias, a capacidade de análise, a comunicação, etc.

\section{b. As justificativas para um direito}

Há fortes razões, portanto, para apoiar a prática da educação em direitos humanos. No entanto, só porque ela é um bem, não é necessariamente um direito. Patinação no gelo é certamente algo bom, mas seria difícil de justificá-la como um direito. (Neste debate, o objetivo é determinar se a EDH é um direito moral, ao invés de avaliar o seu estatuto jurídico).

Há duas maneiras pelas quais a EDH poderia ser classificada como um direito: (1) Há uma justificativa independente para a EDH; (2) A EDH é uma parte inseparável da educação geral.

1 .

Como discutido na seção anterior, os benefícios da EDH podem ser para a sociedade ou para o indivíduo. Neste caso, é melhor dizer sujeitos de direitos ao invés de indivíduos, tendo em vista que em alguns casos nós podemos estar falando de um grupo (como uma comunidade indígena) em vez de uma 
pessoa individual. Há fortes razões para considerar EDH um direito de todos os indivíduos ou grupos que são vítimas de abusos dos direitos humanos. Se a educação em direitos humanos é vista a partir da perspectiva do empoderamento das pessoas para defender e exercer os seus próprios direitos, então há uma forte justificativa fundamentada no direito geral da liberdade da subjugação (que é básico na ação humana) e da opressão e da exploração que lhe são associadas.

Por mais forte que sejam os benefícios sociais, eles não justificam um direito, uma vez que o direito existe (entre outras razões) para proteger os indivíduos contra os cálculos utilitaristas que agregam todos os interesses da sociedade. Os direitos das crianças e os programas de EDH nas escolas podem, em alguns casos, serem baseados na intenção de melhorar o comportamento dos educandos e, consequentemente, tornar a escola mais atrativa para os futuros pais. As formas negativas em que programas de EDH podem se manifestar de acordo com esta lógica são discutidas por Osler e Starkey (2010):

O que passa por educação em direitos humanos em muitos documentos políticos e nas escolas é, na melhor das hipóteses, inadequado, e pode ser pouco mais do que um mecanismo para lidar com o comportamento dos jovens. Um pouco do que é designado como educação em direitos humanos é projetado para incentivar o consenso entre os estudantes, ao invés de promover o pensamento crítico. É possível que as crianças pequenas sejam simplesmente ensinadas a serem gentis umas com as outras, ao invés de lutar por justiça. (OSLER; STARKEY, 2010, p. 17).

Se nós estamos olhando para interesses societários ou globais, uma abordagem mais desejável seria de fato incentivar os estudantes a desenvolver a solidariedade e agir em prol da justiça global. Contudo, estamos então diante de duas diferentes formas de EDH: um espaço para o empoderamento das populações cujos direitos humanos estão sendo violados (claramente um direito); e um espaço para o desenvolvimento de valores de justiça global para aqueles cujos direitos humanos são na maior parte mantidos (certamente desejável, mas difícil de justificar como um direito).

Então, estamos diante de uma situação em que EDH é apenas um direito para aqueles que estão sofrendo abusos dos direitos humanos? Nós só precisaríamos alcançar essa conclusão, se mantemos uma separação injustificada de si e do outro. Os direitos humanos não consistem separadamente de algumas coisas que eu posso reclamar para mim e outras coisas que eu preciso fazer para os outros. Endossar direitos universais é em si uma responsabilidade substancial 
e um compromisso de preservar e defender esses direitos para todos os outros, bem como para si mesmo. (Daí a redundância de afirmar que os jovens devem pensar sobre as suas responsabilidades, bem como os seus direitos - isso só é necessário se não compreendemos a noção de direito). Desse modo, as características do empoderamento e da solidariedade são inseparáveis.

Inevitavelmente a EDH envolverá tanto a capacidade para defender e exercer os próprios direitos, como para respeitar e agir em prol do direito dos outros. (O estudo da Bajaj indicou um caminho em que estes aspectos podem se somar através da coalizão dos estudantes relativamente mais privilegiados trabalhando solidariamente para corrigir os abusos contra os que sofreram maior discriminação.) De forma integrada, a EDH torna-se um direito de todos e não apenas dos mais excluídos (embora a necessidade destes últimos possa aparecer com uma demanda mais imediata). A construção de uma cultura de direitos humanos implica o envolvimento de todos na aprovação dos direitos. Como afirma Freire (1972), os opressores bem como os oprimidos necessitam passar pelo processo de humanização. Magendzo (2005) reflete, portanto, sobre a era do regime de Pinochet no Chile:

Isso me levou a me perguntar por que os únicos que estavam refletindo sobre educação em direitos humanos foram os que sofreram mais durante a repressão. Cheguei à conclusão de que quando a democracia foi recuperada, a educação em direitos humanos deveria ser o centro da educação. Deveria ser o principal objetivo. (MAGENDZO, 2005, p. 138).

Esse ponto é relevante para a segunda questão do valor intrínseco. Só é possível afirmar que algo é o objeto do direito, se houver algum valor intrínseco no objeto. Como temos visto, grande parte da justificação para a EDH a considera como um "direito que capacita", que oferece suporte a outros direitos que têm valor intrínseco. Contudo, os objetos do direito não podem ser puramente instrumentais desta forma. Tomemos o exemplo da EDH, como forma de permitir que as pessoas tenham acesso a informações sobre saúde. Embora este componente educacional seja essencial, o direito, neste caso, é a saúde, tendo a educação simplesmente como parte da estratégia para realizar o direito na prática.

Visualizar a EDH simplesmente como um facilitador dessa forma é uma visão limitada. Se a EDH consiste simplesmente em informar as pessoas sobre os direitos existentes e proporcionar-lhes os conhecimentos necessários para acessá-los, então não podemos justificá-la como um direito em si mesmo. No entanto, como visto acima, há um sentido ativo do sujeito de direitos que neces- 
sariamente envolve conscientização, compreensão e agência, e estes, por sua vez, necessitam de educação. Uma visão mais ampla da EDH a compreende, além do acima exposto, como um processo de reflexão crítica, deliberação e formação dos direitos humanos. Nesse sentido, há um valor intrínseco ao processo, pois é um compromisso com o indivíduo na criação da unidade social da qual faz parte.

Starkey (1991) destaca a "natureza inacabada da obra dos direitos humanos" (p. 16), e expressa esta necessidade dos educandos se envolverem em debates em torno deles:

Os direitos humanos não são um sistema rígido e estático, expressam um conceito dinâmico que implica, por um lado, a preservação das liberdades e do outro um impulso em direção à justiça. Equipados com os princípios dos direitos humanos e um conhecimento das lutas envolvidas em sua conquista, cidadãos de todas as idades podem debater o que é que eles querem manter e o que é que precisa mudar. O passado e o futuro estão em tensão criativa em torno da noção de direitos humanos. (STARKEY, 1991, p. 16).

As crianças em Tamil Nadu, dessa forma, equipadas com os princípios dos direitos humanos, aplicaram-nos em seu contexto específico e coletivamente desenvolveram estratégias para lidar com a discriminação. (BAJAJ, 2011). O debate, portanto, possibilita uma ação mais eficaz contra os abusos dos direitos humanos, trabalhando em conjunto e não individualmente. No entanto, há outro papel para o debate, e que constitui o seu valor intrínseco. Deliberação é constitutiva, em vez de instrumental na defesa dos direitos humanos. Os direitos humanos são formados e mantidos através da própria discussão pública, e a deliberação é uma instanciação dos direitos humanos.

2.

Um caminho alternativo para essa questão é considerar se a EDH é uma parte essencial da educação de um modo geral (tendo como certo que temos o direito humano à educação). Minha justificativa para o direito à educação, em geral, tem resistido à especificação das disciplinas, tais como a geografia ou a química, dada a sua particularidade em relação ao tempo e lugar. Dada a necessidade da educação como um direito de se adaptar a si mesma às diferentes culturas, tempos e indivíduos, coloca-se a necessidade de sua abertura em relação aos conteúdos. Mas há alguma forma em que currículo como um todo pode ser permeado pela EDH? 
Se tomarmos uma visão abrangente da EDH, podemos ver como ela pode constituir uma parte integrante da educação de um modo geral. Duas características da educação são fundamentais aqui: primeiro, a que envolve alguma forma de reflexão coletiva, em observar, analisar e tentar compreender a natureza dos fenômenos através da comunicação; segundo, a que é inerentemente à moral. Por moral, eu não quero dizer que é sempre moralmente bom (pelo menos não na prática), só que sempre há um significado na esfera moral e política. Esta ideia segue a visão de Paulo Freire da impossibilidade da neutralidade na educação:

Não há nem jamais houve prática educativa em espaço-tempo nenhum de tal maneira neutra, comprometida apenas com ideias preponderantemente abstratas e intocáveis. Insistir nisso e convencer ou tentar convencer os incautos de que essa é a verdade... é uma prática política indiscutível... (FREIRE, 1994, p. 65).

A partir desses pontos, podemos ver que a educação geral sempre envolverá a reflexão sobre a sociedade e o indivíduo, a formação das personalidades e a criação de ideias que são moralmente e politicamente significativas. O domínio moral e político, com certeza, é maior do que os direitos humanos, mas deverá necessariamente haver alguma consideração das prerrogativas fundamentais que devem ser garantidas a todos os seres humanos. Educação, portanto, sempre irá aproximar os educandos (e os educadores) ou distanciá-los da cultura de direitos humanos almejada pelos defensores.

Somado a esses pontos está o princípio da indivisibilidade dos direitos acima referidos, de que o direito à educação deve, necessariamente, ser coerente com o conjunto integral dos direitos humanos, e, portanto, os processos representarão positivamente assim como abster-se-ão da violação de outros direitos humanos. A experiência de viver num ambiente onde os direitos são respeitos é, em si, uma significativa fonte de aprendizagem dos direitos humanos, como será explorado mais adiante na seção que se segue.

Há, portanto, uma base sobre a qual se justifica a educação em direitos humanos como um direito, tanto em um sentido independente, e como parte integrante da educação como um todo. A seção seguinte irá extrair as implicações desses argumentos para as abordagens, métodos e práticas da educação em direitos humanos. 


\section{Como educação em direitos humanos?}

\section{Proximidade}

A fim de compreender as diferentes formas de educação em direitos humanos, vou recorrer a um parâmetro usado anteriormente em relação à educação para a cidadania. (MCCOWAN, 2009). A noção de proximidade é uma forma de entender a relação entre fins e meios na educação, entre os principais objetivos e as atividades organizadas para alcançá-los. Na maioria das vezes, nós compreendemos a relação entre o primeiro e o último em um sentido causal: nós selecionamos os métodos que nos possibilitarão a melhor chance para atingir nossos objetivos. Esta relação eu denomino de separação. Embora pareça uma abordagem lógica, tem limitações enquanto o meio mais eficaz pode não ser moralmente válido (como no ditado "os fins justificam os meios"). Um exemplo aqui seria o uso do castigo corporal e o medo da humilhação na sala de aula como formas de motivar os educandos a memorizar de forma mais eficaz os artigos da Convenção sobre os Direitos da Criança (!)

Uma abordagem alternativa para a formação dos meios é denominada harmonia. Neste caso, os meios devem estar em consonância com os princípios de valor contidos nos fins. Assim, as atividades educacionais projetadas para promover a compreensão dos direitos humanos precisam estar imbuídas dos princípios dos direitos humanos. (TOMAŠEVSKI, 2001). Esta forma irá também envolver a exemplificação dos direitos humanos na própria prática dos professores e na gestão da escola. Este modo também é enfatizado na Anistia Internacional:

O conceito de uma educação através dos direitos humanos oferece um claro suporte para uma abordagem que vai além do ensino de direitos humanos na sala de aula para a representação dos direitos humanos nas políticas e práticas cotidianas. (AMNESTY INTERNATIONAL, 2009, p. 12).

Há, portanto, implicações significativas para o papel dos professores no EDH. De acordo com o estudo de Bajaj, grande parte do sucesso do programa teve a ver com a representação dos direitos humanos através do comportamento dos professores, em seu suporte nas intervenções e no convencimento da comunidade em relação à legitimidade da ação. Os professores também descreveram 
seu próprio desenvolvimento, como resultado do ensino de programas de EDH, uma indicação da natureza dinâmica do processo.

A pedagogia participativa é frequentemente justificada com base na sua eficácia para a aprendizagem. Como Tibbetts (2002, p. 162) afirma, a "abordagem pedagógica interativa" está "[...] ligada mais fortemente com a mudança de atitude ou de comportamento do que com uma abordagem puramente de transmissão". Embora importante, este não é o único motivo pelo qual os métodos participativos devem ser adotados em sala de aula. Eles devem ser adotados principalmente porque incorporam o princípio da participação, que é por si só um direito humano.

A harmonia é apoiada no âmbito da Carta do Conselho da Europa:

Práticas e atividades de ensino e aprendizagem devem seguir e promover os valores e os princípios democráticos e de direitos humanos; em particular, a gestão das instituições de ensino, incluindo as escolas, deve refletir e promover os valores dos direitos humanos e fomentar o empoderamento e a participação ativa dos educandos, os professores e a comunidade escolar, incluindo os pais. (CARTA do Conselho da Europa..., 2010).

Aspectos importantes aqui enfatizados são a incorporação dos direitos humanos na pedagogia e na gestão, e o amplo envolvimento da comunidade na tomada de decisão educacional, considerado como um papel de empoderamento em si mesmo. Em outros lugares, a importância da participação para a aprendizagem é ainda mais enfatizada:

Os Estados membros devem promover a gestão democrática em todas as instituições de ensino, tanto como um método desejável e benéfico de governo em seu próprio direito, assim como um meio prático de aprender e experimentar a democracia e o respeito pelos direitos humanos. (CARTA do Conselho da Europa..., 2010).

Há evidências abundantes dessa aprendizagem através de uma gestão democrática, nas 'escolas que respeitam os direitos' no Reino Unido e em outros lugares. (COVELL, 2010; COVELL; HOWE, 2001). Harmonia também se manifesta nas políticas de acesso às escolas e aos sistemas, quer promovendo a inclusão de todos os grupos sociais ou discriminando com base no gênero, 
na raça/etnia, nas habilidades e em uma série de outros fatores, levando ou à exclusão total do sistema escolar ou a uma educação de má qualidade.

Após separação e harmonia vem unificação. Neste terceiro modo, os processos de ensino não são mais distintos das próprias práticas. Desta forma, o ato de exercitar os direitos humanos - reivindicando, construindo e defendendo - é em si uma fonte de aprendizado. As crianças no estudo de Bajaj aprendem não só a partir do programa EDH em termos de aquisição de conhecimentos e habilidades úteis (separação), mas também experimentam a construção dos direitos humanos dentro da escola (harmonia), e através dos processos de reivindicação e intervenção dos direitos fora da escola (unificação) aprendem sobre a ação coletiva, estratégias de mudança, de negociação e assim por diante.

Não há uma clara hierarquia entre os três. No entanto, conforme descrito acima, na educação em direitos humanos - e em qualquer forma de educação envolvendo valores - o modo de separação é altamente problemático.

Esse esquema permite-nos compreender o parâmetro "sobre, para e através de" mais claramente. (AMNESTY INTERNATIONAL, 2009; LOHRENSCHEIT, 2002). Educação 'através' dos direitos humanos é um exemplo de harmonia se ela ocorre dentro do ambiente escolar, e de unificação se ocorre fora de uma instituição ou experiência educacional. Tanto o ensino 'sobre' como o 'para' se referem ao futuro, visto que visam dotar os estudantes com as habilidades necessárias para exercer e defender os direitos humanos em um ponto posterior no tempo, e, portanto, carregam o risco de cair no modo de separação. Contudo, eles ainda podem incorporar os princípios dos direitos humanos em seus processos e, assim, representar a harmonia (e essa incorporação é bastante evidente nas discussões da abordagem "para" os direitos humanos). Assim, nestes casos, requer-se a atenção para a relação professor-aluno, as formas da pedagogia e o processo de construção do currículo, bem como o cenário mais amplo de tomada de decisões nas instituições e no sistema. Na prática, vamos precisar de todos esses três. Os estudantes necessitam de algum conhecimento proposicional dos direitos humanos (sobre), para desenvolver certas habilidades (para) e ter experiências reais de ambientes em que os direitos são respeitados (através).

\section{Flexivel versus fixo}

Sem dúvida, a educação sobre os direitos humanos precisa se constituir numa reflexão crítica sobre o conhecimento, ao invés de uma simples absorção. O binário de transmissão/construção, na verdade, tem dois componentes: a concepção de direitos humanos e a abordagem pedagógica para comunicar esta concepção. Ambas podem ser mais ou menos críticas ou conformistas, abertas ou fechadas, flexíveis ou fixas. (A associação destes termos em cada caso faz 
com que o primeiro pareça mais desejável, mas eu não estou sugerindo, em cada caso, que a rejeição das concepções atuais é sempre preferível). Portanto, há uma variedade de concepções de direitos humanos a partir, de um lado, de uma lista universal fixa, que baseia a sua legitimidade no que está consagrado na lei, e que não pode ser adicionado ou subtraído, para, por outro lado, um processo inteiramente desenvolvido de baixo para cima a partir de lutas e reivindicações de direitos, definidos localmente. No âmbito pedagógico varia de um modelo de transmissão pura, onde o professor transmite conhecimentos objetivamente válidos, absorvidos fielmente pelos estudantes, para, por outro lado, um processo de aprendizagem que começa com uma folha em branco e com a construção coletiva de ideias durante o processo educacional.

Não seria certo impor uma hierarquia sobre eles, ou sugerir que há um valor em incentivar os alunos a rejeitar os instrumentos de direito internacional sem nenhuma reflexão. Nem estou sugerindo que os professores nunca devem transmitir conhecimentos aos estudantes. No entanto, a educação em direitos humanos deve considerar o educando como um sujeito no sentido Freiriano, alguém que é um agente de sua própria aprendizagem, e, respectivamente, um agente nos processos políticos. Em última análise, os direitos humanos só têm valor se forem endossados pelos seres humanos, e verdadeiro endosso (em vez de absorção irrefletida) depende de uma discussão aberta e de uma reflexão crítica.

\section{Processo}

A importância da consonância entre os direitos humanos e os estilos de ensino, a tomada de decisão e o ambiente mais amplo dentro da instituição de ensino, nos leva a uma consideração do processo. Embora não tenha havido espaço aqui para abordar totalmente este ponto, em um artigo anterior. (MCCOWAN, 2010) argumentei que o direito à educação é um direito de processos de aprendizagem significativa, em vez de um direito de insumos educacionais ou níveis específicos de aquisição da aprendizagem. Esta abordagem vai contra a compreensão dominante do direito educacional proposto pelas organizações internacionais, particularmente o Banco Mundial, que propôs recentemente a Meta de Aprendizagem do Milênio em termos de resultados universais em testes de matemática, linguagem e ciências. (FILMER et al., 2006). Dada a necessidade de proteger a abertura e espontaneidade da educação, e valorizar uma ampla gama de resultados, além dos estreitos resultados cognitivos, precisamos incorporar uma concepção de experiência de aprendizagem como sendo válida em si mesma. Estes processos, sem dúvida, conduzem a benefícios posteriores para os educandos, mas são benefícios abertos e talvez inesperados, ao invés de serem universalmente estipulados ou pré-definidos. 
Essa ênfase no processo de aprendizagem é aquela que sintoniza com a discussão acima sobre a educação em direitos humanos. Focar em harmonia e unificação implica na preocupação com a qualidade da própria experiência - proteger a liberdade de expressão dos estudantes, sua integridade física, sua dignidade e assim por diante - em vez de simplesmente subordinar (ou em alguns casos, sacrificar) o momento de aprendizagem para um suposto benefício futuro. Além disso, o processo de discussão dos direitos humanos na sala de aula não é significativo apenas na medida em que possibilita potencializar a ação política, posteriormente fora da escola, ele é válido em si mesmo, como uma instância de investigação aberta e ética do coletivo.

\section{Conclusão}

O modo como vemos a educação em direitos humanos depende da nossa compreensão do que são os direitos humanos. Se os direitos humanos são concedidos de cima para baixo, e sua concretização decorre de sua formulação legal, então a resposta mais adequada é a de ver, analisar e interiorizar a lei. No entanto, se entendermos os direitos humanos como sendo construídos, debatidos e revistos através de deliberação, então uma abordagem educacional muito diferente emerge. A partir desta última perspectiva, a educação serve como um espaço para desenvolver as habilidades, conhecimentos e disposições para participar ativamente na deliberação sobre os direitos humanos na sociedade em geral. Mas esta é apenas uma maneira de ver o processo educativo. Espaços educativos não são apenas locais de preparação para a sociedade em geral, mas são arenas da sociedade em seu próprio direito. Desta forma, os direitos humanos são, na verdade, construídos e se expressam nas deliberações e experiências mais amplas na escola.

Como discutido acima, a educação envolve, necessariamente, direitos humanos, neste caso ela terá sempre implicações morais, que manterá ou violará os direitos humanos e as liberdades. A educação é, necessariamente, um compromisso moral, e envolverá questões do nosso relacionamento com os outros e do modo como agimos em relação a eles, portanto, envolve direitos humanos ou outras possíveis abordagens de justiça. O direito à educação - o direito de exploração da realidade - é um direito à educação em direitos humanos - uma exploração da moral e política vivida. Por outro lado, o exercício e a defesa dos direitos humanos sempre envolverão um aprendizado. Essa dialética é uma encarnação do binômio reflexão-ação acima referido. 
Então isso torna a educação irrelevante? Se nós aprendemos pela ação, para que ter escolas, oficinas e aulas? Por que é que toda a harmonia não se torna unificação? A resposta está na necessidade de passar de um círculo vicioso para um ciclo virtuoso. A educação formal e não formal - qualquer forma de aprendizagem intencional - ainda é necessária para enfrentar e quebrar os padrões de hostilidade, fragmentação e a ausência de consciência que muitas vezes caracterizam as nossas sociedades e relações. Intervenções são necessárias para promover uma espiral em direção à compreensão e ação ética, ausentes de abuso e preconceito.

Educação organizada torna cada vez mais desnecessária na medida em que a sociedade sustenta a aprendizagem em todos os seus espaços, e incorpora a ação ética. Ativistas e educadores de direitos humanos, desta forma, trabalham em direção à criação de uma cultura de direitos humanos, que é em si uma cultura de aprendizagem. Esta, portanto, é a maneira que o direito humano à aprendizagem e a aprendizagem dos direitos humanos torna-se unificada. A vida vivida em toda a sua totalidade é caracterizada por constantes aprendizados, e o aprendizado em si não está separado da vida.

\section{REFERÊNCIAS}

AMNESTY INTERNATIONAL. Guidelines for Human Rights Friendly Schools. London: Amnesty International Publications, 2009.

BAJAJ, M. Schooling for Social Change: The Rise and Impact of Human Rights Education in India. New York: Continuum, 2011.

CARTA do Conselho da Europa sobre a Educação para a Cidadania Democrática e a Educação para os Direitos Humanos. Conselho da Europa, 2010. Disponível em: $<$ http:// www.coe.int/t/dg4/education/ede/Source/Charter/EDC_Charter2_PT.pdf $>$. Acesso em: 03 mar. 2015.

COVELL, K. School Engagement and Rights-Respecting Schools. Cambridge Journal of Education, v. 40, n. 1, p. 39-51, 2010.

COVELL, K.; HOWE, B. Moral education through the 3 Rs: Rights, respect and responsibility. Journal of Moral Education, v. 30, n. 1, p. 29-41, 2001.

DECLARAÇÃO Universal dos Direitos Humanos. Nações Unidas, 1948. Disponível em: <http://www.direitoshumanos.usp.br/index.php/Declara\%C3\%A7\%C3\%A3o-Universal-dos-Direitos-Humanos/declaracao-universal-dos-direitos-humanos.html>. Acesso em: 03 mar. 2015. 
FILMER, D.; HASAN, A.; PRITCHETT, L. A Millennium Learning Goal: Measuring real progress in education (Working Paper 97). Washington, DC: Center for Global Development, 2006.

FREIRE, P. Pedagogy of the Oppressed. London: Sheed and Ward, 1972.

FREIRE, P. Pedagogy of Hope: Reliving Pedagogy of the Oppressed. New York: Continuum, 1994.

HAYDON, G. The Right to Education and Compulsory Schooling. Educational Philosophy and Theory, v. 9, n. 1, p. 1-15, 1977.

LOHRENSCHEIT, C. International Approaches in Human Rights Education. International Review of Education, v. 48, n. 3-4, p. 173-185, 2002.

MCCOWAN, T. Rethinking Citizenship Education: a Curriculum for Participatory Democracy. London: Continuum, 2009

MCCOWAN, T. Reframing the universal right to education. Comparative Education, v. 46, n. 4, p. 509-525, 2010.

MCCOWAN, T. Education as a human right: principles for a universal entitlement to learning. London: Bloomsbury, 2013.

OSLER, A.; STARKEY, H. Teachers and Human Rights Education. Stoke-on-Trent: Trentham, 2010.

PETERS, R. S. Ethics and Education. London: Allen \& Unwin, 1966.

SEN, A. Elements of a Theory of Human Rights. Philosophy and Public Affairs, v. 32, n. 4, p. 315-356, 2004.

STARKEY, H. (Ed.). The Challenge of Human Rights Education. London: Cassell, 1991.

TIBBITTS, F. Understanding what we do: emerging models for human rights education. International Review of Education, v. 48, n. 3-4, p. 159-171, 2002.

TOMAŠEVSKI, K. Human Rights in Education as Prerequisite for Human Rights Education (Right to Education Primer No. 4). Lund and Stockholm: Raoul Wallenberg Institute and SIDA, 2001.

WRINGE, C. The Human Right to Education. Educational Philosophy and Theory, v. 18, n. 2, p. 23-33, 1986.

WALDRON, F.; RUANE, B. Human Rights Education: Reflection on Theory and Practice. Dublin: The Liffey Press, 2011.

Texto recebido em 11 de fevereiro de 2015. Texto aprovado em 24 de fevereiro de 2015. 